\title{
Ethnic aspects of acute primary angle closure in a UK multicultural conurbation
}

\begin{abstract}
Aim To investigate the incidence and ethnic distribution of patients with symptomatic acute primary angle closure (APAC) who presented to a UK hospital serving a multicultural conurbation by a populationwide case series investigation.

Methods Case series chart review of patients aged 30 years and above, who required laser peripheral iridotomy (LPI) for a primary acute angle closure event over a 7-year period. Demographic data for cases were compared to the local resident census data.

Results A total of 46 local residents aged $\geqslant 30$ years required LPI for APAC. In all, $96 \%$ of patients were Caucasian compared to the local resident population of $89 \%$ Caucasian. The overall annual APAC rate for Bolton was 4.14 cases per 100000 population (95\% CI 3.035.52). The standardised incidence ratio for the South Asian population was 0.78 (95\% CI 0.024.34) and 26.6 (95\% CI 0.67-148.40) for the Chinese population.

Conclusions APAC incidence in South Asians was similar to that among Caucasians. The incidence of APAC patients treated in this UK department is consistent with international experience. Individuals of Chinese ethnicity were at an enhanced risk of APAC. However, these results should be interpreted with caution, as patient numbers are small.
\end{abstract}

Eye (2005) 19, 1271-1275. doi:10.1038/sj.eye.6701759; published online 26 November 2004

Keywords: glaucoma; ethnicity; incidence; angle-closure; epidemiology

\section{Introduction}

The prevalence of glaucoma varies by region and race, with open-angle glaucoma more frequent among persons of West African
S Ramesh1, C Maw', CJ Sutton², JR Gandhewar' and SP Kelly ${ }^{1}$

descent and angle-closure glaucoma (ACG) more frequent among South Asian ${ }^{1-3}$ and Inuit ${ }^{4}$ populations. Up to $10 \%$ of Inuit/Eskimo women and $2 \%$ of men over 40 years are affected by ACG. ${ }^{4}$ ACG is thought to affect approximately 1.5 million people worldwide. ${ }^{5}$

ACG incidence is high among people of Asian heritage. ${ }^{1-3}$ An island-wide survey in Singapore reported incidence rates of acute primary angle closure (APAC) at 12 cases per 100000 per year in those aged 30 years and older. ${ }^{1}$ In that study and in a subsequent hospital admission-based study, Singaporean residents of Chinese ethnicity were at highest risk, followed by Malays and Indians who had identical rates of incidence of 6.0 cases per 100000 per year. ${ }^{2,6}$ The Vellore Eye Study (VES) investigators reported a prevalence of $4.3 \%$ (95\% CI 3.0-5.6\%) of primary angle closure glaucoma (PACG) in Southern India, all of which were of the chronic type. ${ }^{3}$ Caucasians are thought to have lower rates of PACG. In a Welsh valley population study in 1966, the prevalence rate for PACG for Caucasian individuals over 40 years was $0.09 \% .^{7}$ The prevalence rate in Northern Italy, including both chronic and occludable angles was similar for residents over 40 years at $0.6 \% .^{8}$ ACG is uncommon in AfroCaribbean individuals who are, however, at enhanced risk of primary open angle glaucoma. $^{9}$

ACG can present dramatically as an acute angle-closure event, with high intraocular pressure, or insidiously as chronic angle closure. The Working Group for defining Glaucoma of the International Society of Geographical and Epidemiologic Ophthalmology proposed that the classification of PACG be revised for consistent use in population-based studies. ${ }^{10}$ It is recommended that the term 'primary angle closure glaucoma' be restricted to patients with both glaucomatous optic neuropathy and a reproducible visual field
${ }^{1}$ Department of Ophthalmology, Bolton Hospitals NHS Trust, Royal Bolton Hospital, Bolton, UK

${ }^{2}$ Lancashire Postgraduate School of Medicine and Health (LPSMH), University of Central Lancashire, Preston, UK

Correspondence: S Ramesh, Department of Ophthalmology, Bolton Hospitals NHS Trust, Royal Bolton Hospital, Farnworth, Bolton, UK Tel/Fax: +44 1204390390 .

Received: 1 June 2004 Accepted: 23 September 2004

Published online: 26 November 2004 
defect. Those with an acute, reversible event of elevated intraocular pressure should be considered as having APAC. ${ }^{10}$ Based on this classification, manifest PACG prevalence was found to be $0.5 \%$ (95\% CI $0.1-0.9 \%$ ) in the VES $^{11}$ and $0.7 \%$ in the population over 30 years in the Andhra Pradesh Eye Disease Study (95\% CI 0.34-1.31\%). ${ }^{2}$ These rates are comparable to studies from Singapore $(0.8 \%)^{12}$ and Mongolia $(0.8 \%)^{13}$

Foster and Johnson estimate that the number of persons with 'occludable' angles in China, based on previous population-based studies in Mongolia and the Tanjong Pagar district of Singapore, is 28.2 million, whereas 9.1 million have significant angle closure. ${ }^{12-14} \mathrm{~A}$ recent study from Thailand suggests that ACG accounts for at least $21 \%$ of all glaucomas there ${ }^{15}$ In spite of the blinding potential of this disease, local public awareness appeared to be low leading to late presentation. ${ }^{16}$

As the literature on the epidemiology of ACG is varied, investigating the incidence of ACG by ethnicity in multicultural environments is relevant. We considered that the acute presentation of the disease, that is, the demand incidence for treatment for APAC by ethnic origin might perhaps be a crude marker for the underlying prevalence of PACG by ethnicity in the local community. We also had the internal organisational objective of wishing to ascertain if access to acute services for APAC cases by ethnic origin reflected the local population's ethnic mix.

\section{Methods}

The study was conducted by retrospectively examining the case notes of all Bolton residents who presented to Bolton Hospitals NHS Trust requiring a laser peripheral iridotomy (LPI) in 7 years from 1st January 1995 to 31st December 2001. Cases were ascertained by a combination of searching the Hospital Episode Statistics returns for OPCS-4 operations (Code C 62.3 laser iridotomy) and the International Classification of Disease-10 for diagnosis (code H40.2 Glaucoma; PACG) and additionally by hand searching of the laser surgery treatment record registers. Details are recorded in our treatment register both by OPCS -4 code and in free text format by the treating surgeon. Case notes of all patients who underwent LPI were examined. Only patients who had an LPI for a confirmed APAC event and who had a Bolton

Metropolitan home postcode were included in this study.

The diagnosis of APAC was clinical and comprised a combination of the classical signs and symptoms of an acute attack: ocular pain and redness from high intraocular pressure, IOP greater than $22 \mathrm{~mm} \mathrm{Hg}$, frequently associated with symptoms of nausea, vomiting, and with blurring of vision with or without haloes. An intraocular pressure of $22 \mathrm{~mm} \mathrm{Hg}$ or more was an absolute requirement for case ascertainment. The duty consultant ophthalmologist confirmed the diagnosis of primary angle closure on presentation or within a few days thereof. Optic disc and visual field abnormalities were not required for case diagnosis for this audit but were available. The treating clinicians performed gonioscopy or assessment of the anterior chamber by the Van Herrick method.

Patients living outside the Bolton postcode area at the time of LPI treatment were excluded, as were patients who had experienced their acute attack outside of the study dates. Patients with secondary angle closure or pupil block glaucoma, such as neovascular glaucoma or uveitic glaucoma, were also excluded. Standard demographic and ophthalmic data contained in the hospital charts were extracted for all patients. These included date of birth, sex, ethnicity, date of iridotomy, age at time of LPI, etc.

In our department, in keeping with UK-wide NHS practice, ethnicity is recorded as a self-assigned category declared by the patient on registration. It is mandatory that NHS organisations capture such data. ${ }^{17,18}$ The definitions of ethnic groups used are the same as those in the 2001 UK census, that is, white, black Caribbean, black African, black other, Indian, Pakistani, Bangladeshi, Chinese, and 'other ethnic'. Patients are presented with a list of these ethnic group categories from which to identify their self-determined ethnic group. Self-declared country or area of birth is also routinely enquired of within Hospital Episode Statistics returns and was available to us.

Ethnic origin NHS patient self-declarations were then abstracted and grouped as either Caucasian, Southern Asian (which includes people of Indian, Pakistani, and Bangladeshi origin), Chinese, and 'other ethnic' groups. Demographics including ethnicity for all 46 APAC cases requiring LPI was recorded. Ethnicity ascertainment was available to us for all 46 cases. As APAC is rare in those under 30 years of age, we restricted our data analysis to those aged $\geqslant 30$ years. Rates of APAC for the population $\geqslant 30$ years by ethnic groups for the 7-year period were calculated and annual incidence figures were produced. Additionally, standardised incidence ratios (SIR) were calculated using indirect standardisation over strata formed by combinations of age (5-year bands) and sex. ${ }^{19}$ The Caucasian population was used as the standard (comparator) population. Similar rationale has been used by groups from Singapore to estimate incidence rates. ${ }^{6}$

\section{Results}

A total of 46 patients, 13 (28\%) male and 33 (72\%) female, had LPI for APAC in the 7-year study period. In all, 
44 cases $(95.6 \%)$ were Caucasian compared to the Bolton resident population of $92.5 \%$ Caucasian (see Figure 1) in the $\geqslant 30$ years age group. The APAC overall presenting rate was 4.14 cases per 100000 resident population $\geqslant 30$ years per annum (95\% CI 3.03-5.52). Details are in Table 1.

The breakdown of APAC cases over the 7-year period is in Table 2. The crude incidence for males was 2.46 per 100000 per annum (95\% CI 1.31-4.21) and for females was 5.65 per 100000 per annum (95\% CI 3.89-7.93). This is a relative rate of 2.29 for females. For South Asians, the

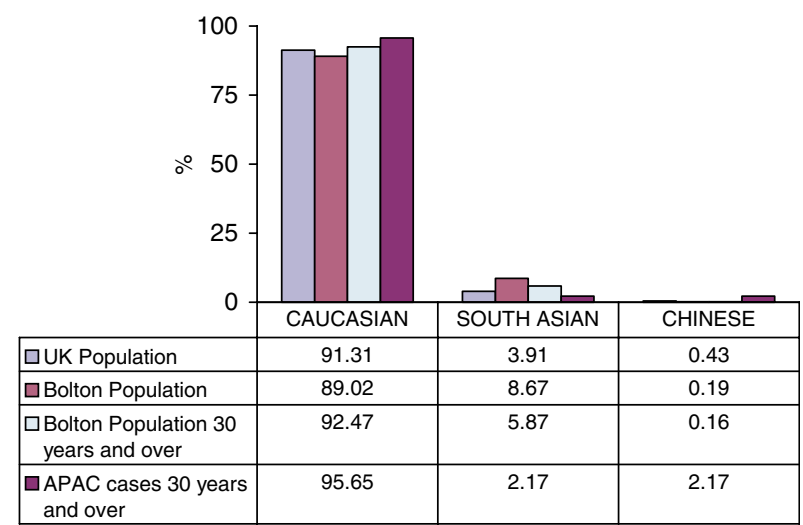

Figure 1 UK and Bolton residents (2001 census) by groups-(1) Caucasian, (2) South Asian, and (3) Chinese, all ages and aged 30 years or over, and incidence of APAC cases aged 30 years and over.

Table 1 Numbers of patients presenting with APAC per year: all ages and ethnic groups

\begin{tabular}{lcccc}
\hline & All ethnic groups & Caucasian & South Asian & Oriental \\
\hline 1995 & 3 & 3 & 0 & 0 \\
1996 & 5 & 5 & 0 & 0 \\
1997 & 7 & 7 & 0 & 0 \\
1998 & 7 & 7 & 0 & 0 \\
1999 & 8 & 7 & 0 & 1 \\
2000 & 6 & 5 & 1 & 0 \\
2001 & 10 & 10 & 0 & 0 \\
Total & 46 & 44 & 1 & 1 \\
\hline
\end{tabular}

age and sex standardised incidence rate was 3.07 (95\% CI 0.08-17.10) per 100000 per year and the SIR was 0.78 (95\% CI 0.02-4.34). Similarly, for the Chinese, the standardised incidence rate was 106.61 (95\% CI 2.67594.03) per 100000 per year and the SIR was $26.63(95 \%$ CI 0.67-148.40). There were no APAC cases recorded among the black population of 1062 residents or in the 649 residents of mixed parentage. Although the overall population sample is large, the absolute number of patients with APAC is small, due to the low disease prevalence. This hampers further statistical elaboration.

\section{Discussion}

Bolton is a former mill town in the north west of England with approximately 260000 residents, of whom almost 160000 are $\geqslant 30$ years and nearly 40000 are 65 years or older. There is a diverse racial mix within the town, with 9\% of the population currently of Indian, Pakistani, or Bangladeshi ethnicity. This is referred to as 'of South Asian ethnicity' in this paper. In all, $14.9 \%$ of the total resident population is aged over 65 years, compared with $5.6 \%$ of Chinese and $4.6 \%$ of the South Asian residents.

Bolton Hospitals NHS Trust has an Accident and Emergency Department and the local Ophthalmology Unit serves the town. Bolton residents with acute ophthalmological disorders are thus almost invariably treated locally in the first instance in our department. Patients with an attack of APAC are usually severely affected enough to seek medical attention, especially if free at the point of delivery of the health system, such as that exists in the UK's National Health Service. Similar rationale has been used to estimate the incidence rate of ACG in other observational studies. ${ }^{6}$ A very small number of patients may seek out treatment with NHS provision. Treatment of APAC involves laser or surgical iridotomy. Laser iridotomy facilities are however only available locally on the Bolton Hospital NHS Trust site. Surgical iridotomy has not been performed as primary treatment for APAC in our unit for over a decade, as in

Table 2 Statistical analysis of presenting APAC cases

\begin{tabular}{|c|c|c|c|c|}
\hline & All residents & Caucasian residents & $\begin{array}{l}\text { Southern Asian } \\
\text { residents }\end{array}$ & Chinese residents \\
\hline Bolton Metropolitan population & 261038 & 232363 & 22640 & 496 \\
\hline $\begin{array}{l}\text { Bolton population aged } 30 \text { years and } \\
\text { over }\end{array}$ & 158899 & 146936 & 9321 & 251 \\
\hline APAC cases aged 30 years and over & 46 & 44 & 1 & 1 \\
\hline $\begin{array}{l}\text { Crude incidence rate }(95 \% \mathrm{CI}) \text { among } 30 \\
\text { years and over per } 100000 \text { per annum }\end{array}$ & $4.14(3.03-5.52)$ & $4.28(3.03-5.63)$ & $1.53(0.04-8.54)$ & $56.92(1.42-317.13)$ \\
\hline $\begin{array}{l}\text { Age-sex standardised rates (per annum } \\
\text { per } 100000 \text { ) }\end{array}$ & - & $4.12(2.99-5.53)$ & $3.07(0.08-17.10)$ & $106.61(2.67-594.03)$ \\
\hline Standardised incidence ratios (SIR) & - & - & $0.78(0.02-4.34)$ & $26.63(0.67-148.40)$ \\
\hline
\end{tabular}


other UK departments. Cataract extraction without the trial of laser iridotomy was not practised in our unit during the study period.

APAC is a genuine ophthalmological emergency, which is never managed in primary care in the UK. ${ }^{20}$ However, we do acknowledge that patients with APAC may not have presented to our unit and thus may have been missed from the study. However, we believe that it is unlikely that differential access to secondary care by ethnicity might be responsible for any observed ethnic variations in the incidence of APAC, as the condition is sufficiently distressing for all affected individuals to seek treatment. Some caution in interpretation of numbers would be prudent as recent studies of primary angle closure in Asian populations have suggested that chronic forms of the condition are more common in these ethnic groups, ${ }^{10,21}$ and also that APAC events lead to more severe outcomes. 22

Our findings are based on a single case in each of the South Asian and Chinese ethnic groups, and so should be interpreted with caution. We believe that the difference in APAC rates calculated is a reflection of the racial aspects of the disease in our local society. It is possible that Bolton residents might have experienced an acute APAC episode requiring emergency treatment while travelling elsewhere or one that resolved spontaneously; this could only be a problem for analysis if it happened differentially between the ethnic groups compared. The former OPCS, now the Office for National Statistics (ONS), population census and the NHS method of recording of ethnicity is a pragmatic methodology. ${ }^{23}$ Both enquiries rely on self-declaration of ethnicity. ${ }^{24}$ As these methods are consistent, it is unlikely to introduce bias into our results.

PACG is considered a worldwide issue. ${ }^{5,10,25}$ Potential confounding problems affecting epidemiological studies of PACG include case selection bias, the variable presentation of the condition in different ethnic groups, and variable case definitions. ${ }^{26,27}$ As in other studies, we found those of Eastern Asian, that is, Chinese ethnicity to be at an enhanced risk of APAC compared to Caucasians. Our absolute number of patients with APAC was small, especially in the non-Caucasian populations. As the Bolton population ages and the age distribution of the South Asian ethnic group becomes similar to the Caucasian distribution, the true risk of APAC in this group may become clearer. Before embarking on largescale screening and treatment campaigns for ACG in Asia, or among ethnic groups living in multicultural locations such as in the UK, it would seem prudent to collect more epidemiological information on the condition. This is particularly important in the context of the Singaporean experience on long-term outcomes ${ }^{22}$ where high rates of blindness after APAC events were recorded. Studies of APAC disease patterns among immigrant groups in multicultural societies might assist international agencies in this respect. Our findings might be considered as an exploratory study that could be extended to other districts with diverse ethnic populations.

\section{References}

1 Seah SK, Foster PJ, Chew PT, Jap A, Oen F, Fam HB et al. Incidence of acute primary angle-closure glaucoma in Singapore - an island-wide survey. Arch Ophthalmol 1997; 115: $1436-1440$.

2 Dandona L, Dandona R, Mandal P, Srinivas M, John RK, McCarty CA et al. Angle-closure in an urban population in Southern India. The Andhra Pradesh eye disease study. Ophthalmology 2000; 107: 1710-1716.

3 Jacob A, Thomas R, Koshi SP, Braganza A, Muliyil J. Prevalence of primary glaucoma in an urban south Indian population. Indian J Ophthalmol 1998; 46: 81-86.

4 Arkell SM, Lightman DA, Sommer A, Taylor HR, Korshin $\mathrm{OM}$, Tielsch JM. The prevalence of glaucoma among Eskimos of North-west Alaska. Arch Ophthalmol 1987; 105 482-485.

5 Congdon NG, Friedman DS. Angle-closure glaucoma: impact, aetiology, diagnosis, and treatment. Curr Opin Ophthalmol 2003; 14: 70-73.

6 Wong T, Foster PJ, Seah SK, Chew PT. Rates of hospital admissions for primary angle closure glaucoma among Chinese, Malays, and Indians in Singapore. Br J Ophthalmol 2000; 84: 990-992.

7 Hollows FC, Graham PA. Intraocular pressure, glaucoma and glaucoma suspects in a defined population. $\mathrm{Br} \mathrm{J}$ Ophthalmol 1966; 50: 570-586.

8 Bonomi L, Marchini G, Marraffa M, Bernardi P, De Franco I, Perfetti $S$ et al. Epidemiology of angle-closure glaucoma: prevalence, clinical types, and association with peripheral anterior chamber depth in the Egna-Neumarket Glaucoma Study. Ophthalmology 2000; 107: 998-1003.

9 Leske C, Connel A, Schachat A. The Barbados eye study: prevalence of open angle glaucoma. Arch Ophthalmol 1994; 112: $821-828$.

10 Foster PJ, Buhrmann RR, Quigley HA, Johnson GJ. The definition and classification of glaucoma in prevalence surveys. Br J Ophthalmol 2002; 86: 238-242.

11 Thomas R, Parikh R, Muliyil J, Kumar RS. Five-year risk of progression of primary angle closure to primary angle closure glaucoma: a population-based study. Acta Ophthalmol Scand 2003; 81: 480-485.

12 Foster PJ, Oen FT, Machin DS, Ng TP, Devereux JG, Johnson GJ et al. The prevalence of glaucoma in Chinese residents of Singapore. A cross-sectional population survey in Tanjong Pagar district. Arch Ophthalmol 2000; 118: 1105-1111.

13 Foster PJ, Baasanhu J, Alsbirk PH, Munkhbayar D, Uranchimeg D, Johnson GJ. Glaucoma in Mongolia-a population-based survey in Hovsgol Province, northern Mongolia. Arch Ophthalmol 1996; 114: 1235-1241.

14 Foster PJ, Johnson GJ. Glaucoma in China: how big is the problem? Br J Ophthalmol 2001; 85: 1277-1282.

15 Bourne RR, Sukudom P, Foster PJ, Tantisevi V, Jitapunkul S, Lee PS et al. Prevalence of glaucoma in Thailand: a 
population based survey in Rom Klao District, Bangkok. $\mathrm{Br}$ J Ophthalmol 2003; 87: 1069-1074.

16 Saw SM, Gazzard G, Friedman D, Foster PJ, Devereux JG, Wong ML et al. Awareness of glaucoma, and health beliefs of patients suffering primary acute angle closure. $\mathrm{Br} \mathrm{J}$ Ophthalmol 2003; 87: 446-449.

17 NHS Executive - Collection of ethnic group data for admitted patients. NHSE: Leeds, 30 September 1994 (Letter EL (94) 77).

18 NHS Executive Information Management Group. Collecting Ethnic Group Data for Admitted Patient Care: Implementation Guidance and Training Material, 2nd edn. Department of Health: London, 1994.

19 Bland M. An Introduction to Medical Statistics, 3rd edn. Oxford University Press: Oxford, 2000; 295-297.

20 Saunders DC. Acute closed-angle glaucoma and Nd-YAG laser iridotomy. Br J Ophthalmol 1990; 74: 523-525.

21 Sihota R, Sood A, Gupta V, Dada T, Agarwal HC. A prospective long term study of primary chronic angle closure glaucoma. Acta Ophthalmol Scand 2004; 82: 209-213.

22 Aung T, Friedman DS, Chew PT, Ang LP, Gazzard G, Lai YF et al. Long-term outcomes in asians after acute primary angle closure. Ophthalmology 2004; 111: 1464-1469.

23 Aspinall PJ. Department of Health's requirement for mandatory collection of data on ethnic group of inpatients. BMJ 1995; 311: 1006-1009.

24 McKenzie K, Crowcroft NS. Describing race, ethnicity, and culture in medical research. BMJ 1996; 312: 1054.

25 Bonomi L. Epidemiology of angle-closure glaucoma. Acta Ophthalmol Scand Suppl 2002; 236: 11-13.

26 Erie JC, Hodge DO, Gray DT. The incidence of primary angle-closure glaucoma in Olmsted County, Minnesota. Arch Ophthalmol 1997; 115: 177-181.

27 Tielsch JM, Sommer A, Katz J, Royall RM, Quigley HA, Javitt J. Racial variations in the prevalence of primary openangle glaucoma. The Baltimore Eye Survey. JAMA 1991; 266: 369-374. 